\title{
Polyfunctional Cubic Silsesquioxanes as Building Blocks for Organic/lnorganic Hybrids
}

\author{
Richard M. Laine,* Chunxin Zhang, Alan Sellinger and Lisa Viculis \\ Department of Materials Science and Engineering and Department of Chemistry, and the Macromolecular \\ Science and Engineering Center, University of Michigan, Ann Arbor, MI 48109-2136, USA
}

Cubic silsesquioxanes, $\left[\mathrm{RSiO}_{1.5}\right]_{x}$, potentially offer access to organic/inorganic hybrids wherein the exact shape, size and mechanical properties of the inorganic component are perfectly defined. Furthermore, by tailoring the organic functionality bound to silicon, the inorganic/ organic interface can also be perfectly defined. Finally, careful selection of the polymerizable groups in the organic moieties can provide goodto-excellent control of the crosslinked density or degree of polymerization of the resulting hybrid materials. Thus, cubic silsesquioxanes may be exceptional model materials for inorganic/organic hybrids. Methods of synthesizing cubes with liquid-crystalline and/or polymerizable organic moieties are described. Some thermal properties are discussed. The catalytic copolymerization of the octavinyldimethylsiloxy-functionalized cube with the octahydridodimethylsiloxy-functionalized cube to produce a material with well-defined microporosity and high surface area is described. (C) 1998 John Wiley \& Sons, Ltd.

Keywords: Cubic Silsesquioxanes; interface; materials; hybrids

Received 27 January 1997; accepted 26 February 1998

\section{INTRODUCTION}

Organic/inorganic hybrids have recently received considerable attention because they offer the opportunity to develop composite materials with properties that are not those expected on the basis of

* Correspondence to: R. M. Laine, Department of Materials Science and Engineering, University of Michigan, Ann Arbor, MI 48109-2136, USA.

Contract/grant sponsor: Federal Aviation Administration (US); Contract/grant number: $95-\mathrm{G}-026$.

Contract/grant sponsor: National Institutes of Dental Research (US).

(C) 1998 John Wiley \& Sons, Ltd. application of the rule of mixtures to the component phases. ${ }^{1,2}$ In essence, this means that the interface(s) between the component phases contribute significantly to the materials properties. Cubic silsesquioxanes, e.g. $\left[\mathrm{RSiO}_{1.5}\right]_{8}$, where $\mathrm{R}$ can be a diverse number of organic groups (Fig. 1), offer the opportunity to develop a wide range of hybrid materials with diverse properties. ${ }^{3-14}$ In principle, the $\left(\mathrm{SiO}_{1.5}\right)_{8}$ core or cube can provide a spatially well-defined, rigid, hard component. Through proper choice of polymerizable $\mathrm{R}$ groups, the organic component can be varied to control the crosslink density about the cube, the segment distances between crosslinks, the packing of individual cubes with respect to each other and also the stability of the cube/organic bond. This type of control offers the potential to probe the effects of variations in interfacial interactions on hybrid properties. Thus, cube-based hybrids may provide a method of careful assessment of the scope and potential of organic/inorganic hybrid materials.

To explore properly the utility of cube hybrids, a set of synthetic methods were developed, as described below, that permit selective modification of the organic groups on the cubes. This allows one to define the properties (e.g. melting point, crystallinity, liquid-crystalline (LC) behavior, thermal stability etc.) of the individual cubes before polymerization. Coincidentally, synthetic methods were developed to introduce reactive groups for selectively linking (polymerizing) the modified cubes to form hybrids wherein the properties of the resulting interfaces are well defined. The next
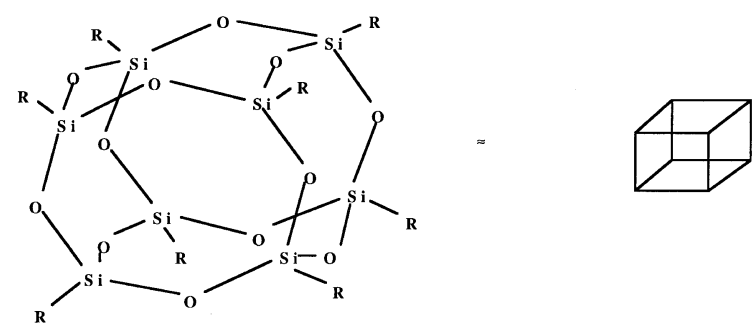

Figure 1 Cubic silsesquioxanes $\left[\mathrm{RSiO}_{1.5}\right]_{8}$. 


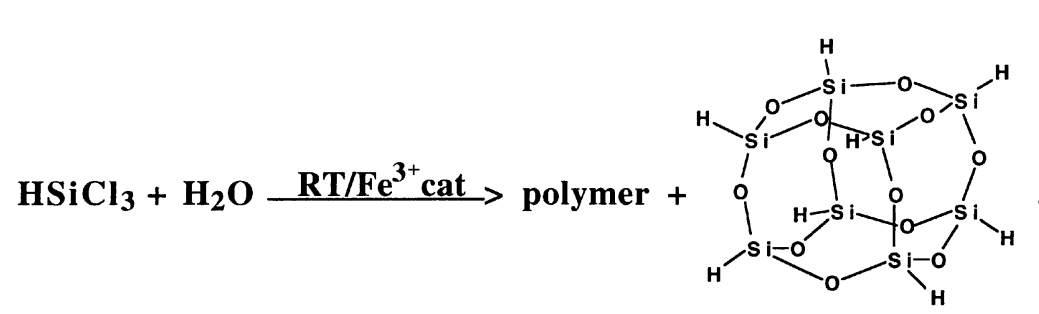

15-20\%

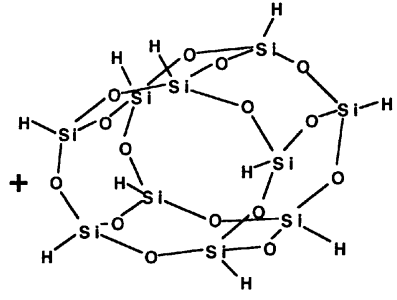

5-10\%

Scheme 1

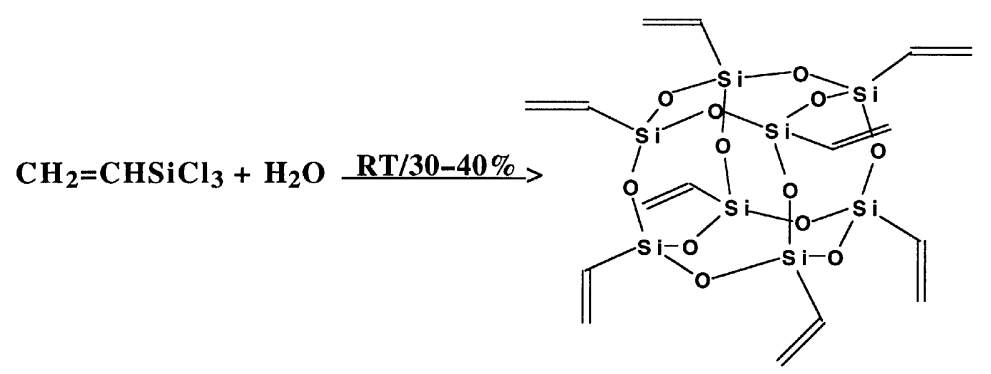

Scheme 2

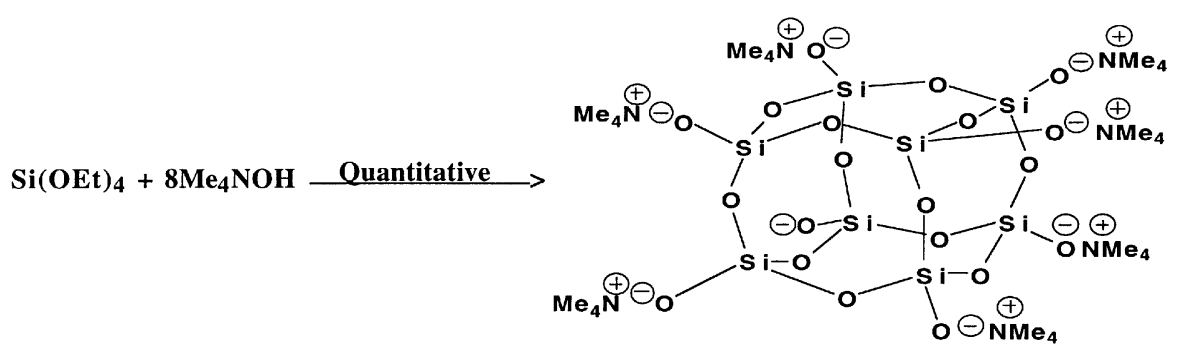

Scheme 3
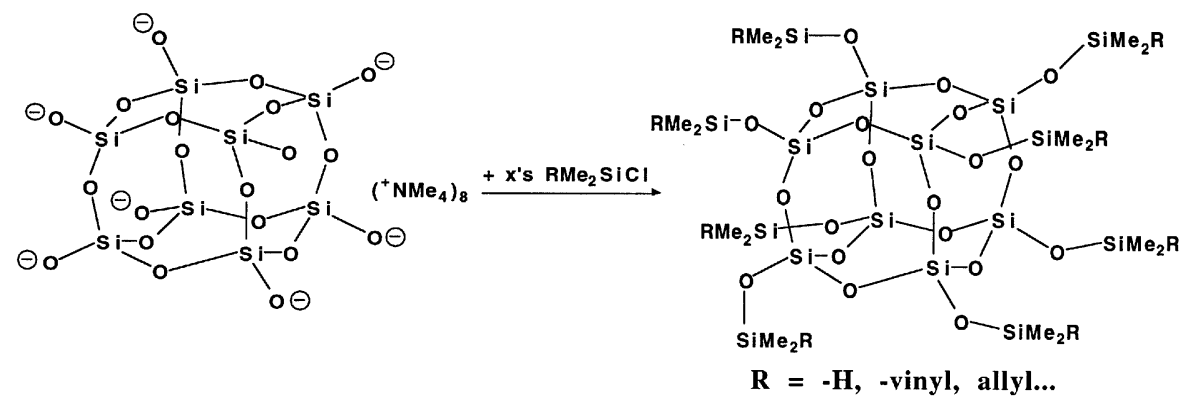

Scheme 4

(C) 1998 John Wiley \& Sons, Ltd.

Appl. Organometal. Chem. 12, 715-723 (1998) 


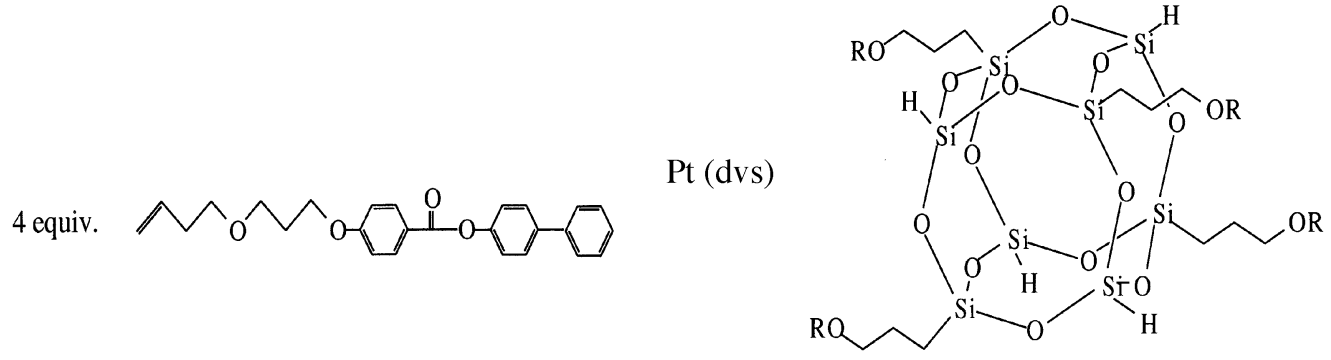

Scheme 5

step in this process is to evaluate the resulting hybrid materials with respect to their chemical, mechanical, optical and other properties. We describe here initial efforts to study simple hydrosilylative polymerization of octafunctional cubes to produce defined interfaces.

\section{BACKGROUND}

Our original research goals were to develop LC- modified cubes that could be polymerized at low temperatures with low shrinkage to provide abrasion-resistant and tough composites that would be potentially useful for dental restoratives. In the course of these studies, we were able to prepare substituted cubes with novel LC properties, ${ }^{10,11}$ good high-temperature stability and controlled porosity, as described below. The first step in this process was to identify simple routes to cubes that are easily modifiable.

Traditional synthesis routes rely on the hydrolysis of alkyl or aryl chloro- or alkoxy-si-

Table 1 Properties of LC Mesogens and their corresponding LC-cubes

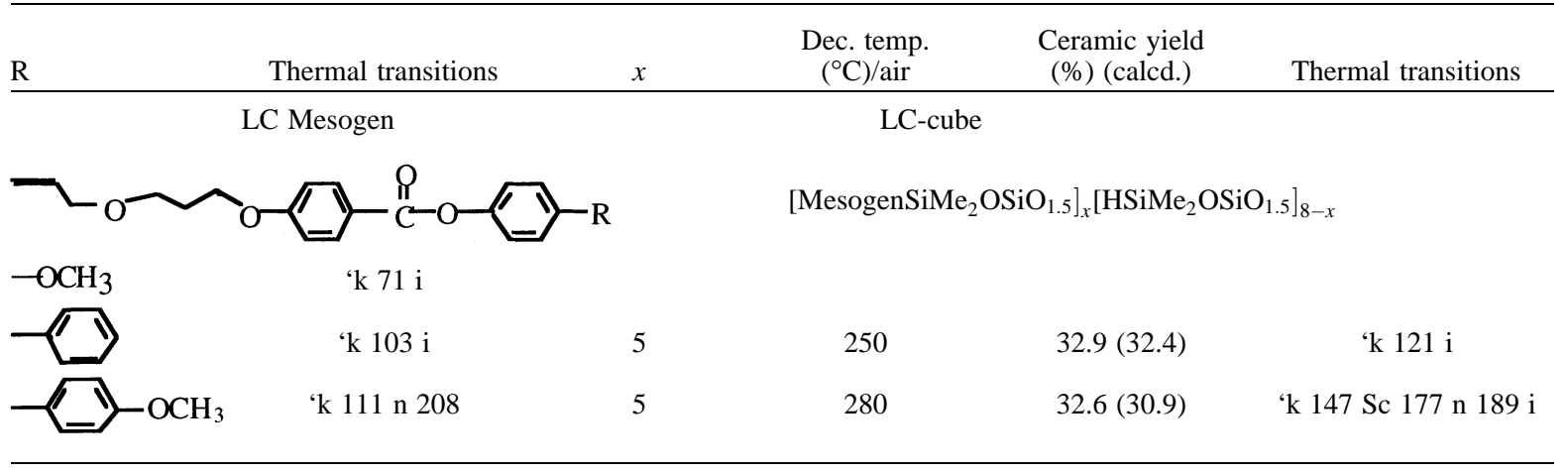

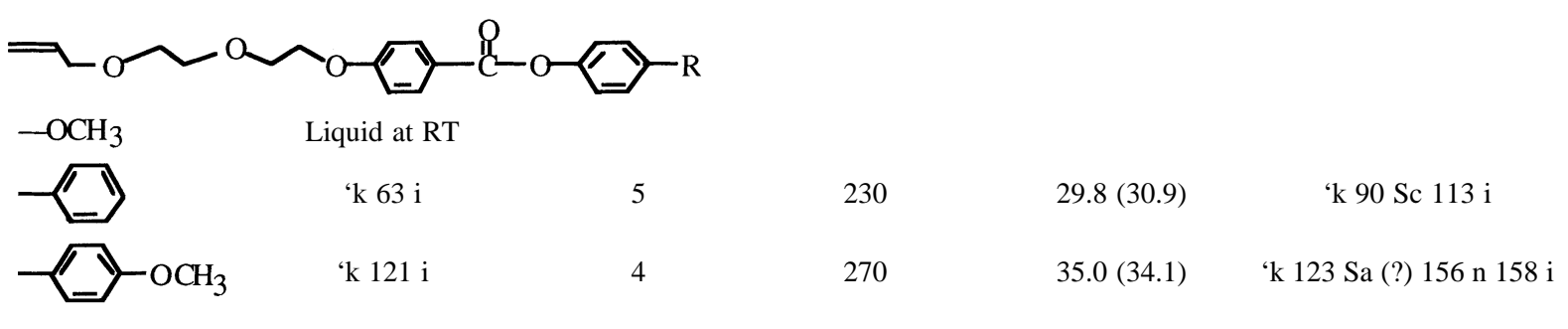

\footnotetext{
${ }^{\text {a }}$ Compared with:

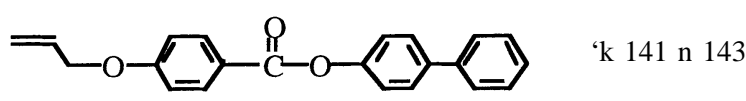




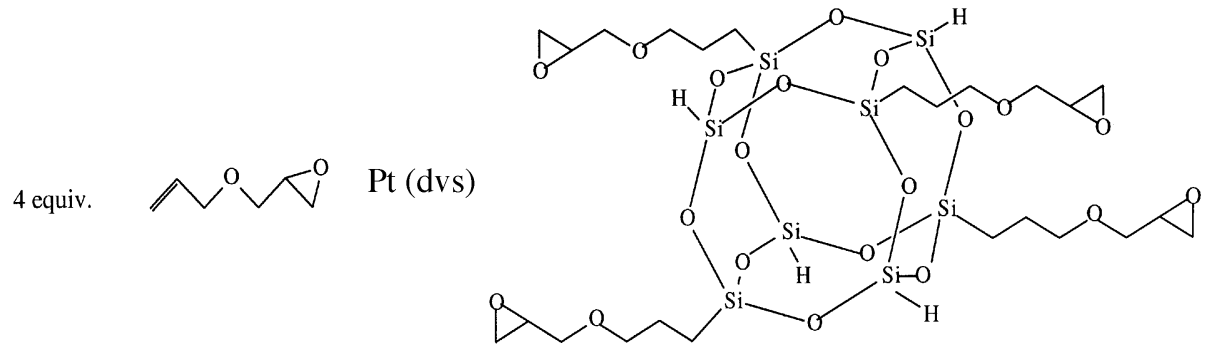

Scheme 6

lanes. ${ }^{3,4,15-19}$ Unfortunately, with few exceptions, one obtains only low-to-moderate yields of octafunctional cubes, as illustrated in schemes 1 and 2. ${ }^{15-19}$

Recently Hasegawa et al., ${ }^{20-22}$ building on earlier work of Hoebbel et al., ${ }^{23,24}$ identified a high-yield route to $\mathrm{Q}_{8} \mathrm{D}_{8}$ cubes as illustrated in (Schemes 3 and 4). The octaanion shown in Scheme 3 can also be made in two steps from various $\mathrm{SiO}_{2}$ sources.

The high yields of the $\mathrm{Q}_{8} \mathrm{D}_{8}$ or 'spacer' cubes makes them very attractive for further study because large quantities can be prepared, so that test samples can be made for evaluation of mechanical properties. One particular advantage of making cubes with $\mathrm{Si}-\mathrm{H}$ groups is that they permit, via hydrosilylation, selective attachment of numerous moieties to the cube framework. This in turn provides sets of modified cubes of use in producing tailored hybrid materials. Given our original goals, we first learned to introduce moieties that induce LC behavior. For comparative purposes, we made cubes using both $\mathrm{H}_{8} \mathrm{~T}_{8}$ and $\mathrm{H}_{8} \mathrm{D}_{8} \mathrm{Q}_{8}$ cubes as the basic starting point. ${ }^{15-22}$

Compounds synthesized by scheme 5 show nematic behavior in the $80-180{ }^{\circ} \mathrm{C}$ temperature range. ${ }^{11}$ More recently, we found that the monomers shown in Table 1 provide cubes with Smectic $\mathrm{C}$ behavior despite the fact that the monomers themselves show either no LC behavior or only nematic behavior. ${ }^{25}$

Unfortunately, the melt ranges still exceed those desirable (below $32{ }^{\circ} \mathrm{C}$ ) for dental restorative applications. However, the cubes that exhibit LC behavior have not yet been modified to permit polymerization. It is expected that the addition of polymerizable groups will reduce the melt range without eliminating the LC behavior. Thus, the next step in our synthesis studies was to learn to prepare cubes that could be photolytically polymerized, again with dental applications in mind. It is important to note that photoreactive cubes are potentially very useful for photolithography, particularly for rapid prototyping.(table 1)

Initial efforts focused simply on making cubes with crosslinkable moieties, but without LC properties. The results of these studies appear to support the idea that these moieties will lower the melt range, as several of them are liquid at room temperature. For example, the $\mathrm{H}_{8} \mathrm{~T}_{8}$ glycidyl derivative produced in Scheme 6, and the related $\mathrm{H}_{8} \mathrm{D}_{8} \mathrm{Q}_{8}$ derivative, are photopolymerizable liquids. ${ }^{13}$ Both compounds polymerize (differential scanning caloimetry, DSC) on heating to above $150{ }^{\circ} \mathrm{C}$. Figures 2 and 3 show that, after polymerization, both materials are stable to temperatures of $220-250^{\circ} \mathrm{C}$.

In general, the epoxide and methacrylate derivatives we have made are stable to temperatures ranging from $220^{\circ}$ to $280^{\circ} \mathrm{C}$. The addition of the $-\mathrm{Me}_{2} \mathrm{SiO}$ - spacer tends to reduce the overall thermal stability by about $30-50{ }^{\circ} \mathrm{C}$. However, in one instance this is not the case. Vinylcyclohexenyl derivatives (Scheme 7, tetra- to hexa-substituted) melt in the $50-70{ }^{\circ} \mathrm{C}$ range, crosslink on heating to temperatures of $250{ }^{\circ} \mathrm{C}$ and are stable to $\approx 400{ }^{\circ} \mathrm{C}$ in air as suggested by the TGA shown in Figure 4 (L. Viculis, C. Zhang and R.M. Laine, unpublished work). Of further interest is the fact that after a $250{ }^{\circ} \mathrm{C} / 3 \mathrm{~h} /$ nitrogen cure, samples of the tetravinylcyclohexenyl material are flexible. This hightemperature stability, combined with the flexibility and ease of synthesis, suggests potential for aerospace applications. More work needs to be done, first to find out why they are more stable by almost $200{ }^{\circ} \mathrm{C}$ than all of the other spacer cube materials made to date so that new analogues can be made, and then to learn to control their mechanical properties. Our goals in this area are to increase stability by at least $100{ }^{\circ} \mathrm{C}$ without sacrificing any potential mechanical properties. In general, DTA and thermal studies give us a global idea of how 


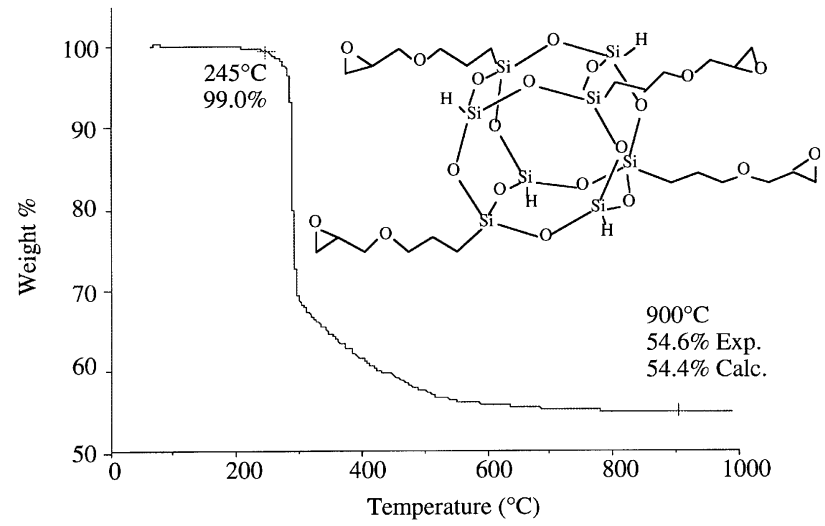

Figure 2 Thermogravimetric analysis (TGA) of (glycidyl $)_{4} \mathrm{H}_{4} \mathrm{~T}_{8}$ cube. Note, average substitution $n=4$, as supported by the found ceramic yield vs. that calculated for the tetrasubstituted compound and NMR analysis.

these materials polymerize; however, given that our goal is to develop a detailed understanding of both polymer structure and interfacial interactions, we recently began detailed studies on the polymerization of some simple octafunctional cubes, beginning with the polymerization of $\mathrm{H}_{8} \mathrm{D}_{8} \mathrm{Q}_{8}$ with vinyl ${ }_{8} \mathrm{D}_{8} \mathrm{Q}_{8}$.

\section{RESULTS AND DISCUSSION}

The $\mathrm{H}_{8} \mathrm{D}_{8} \mathrm{Q}_{8} /$ vinyl ${ }_{8} \mathrm{D}_{8} \mathrm{Q}_{8}$ couple can be hydrosilylatively polymerized (Scheme 8 ) at room temperature using $2 \mathrm{mM}$ bis(tetramethyldivinylsiloxane) platinum in toluene as catalyst. ${ }^{26,27}$ Typically, $1.4 \mathrm{mmol}$ of each cube is dissolved in $40 \mathrm{ml}$ of toluene under nitrogen $0.7 \mathrm{~mL}$ of catalyst is added at $0{ }^{\circ} \mathrm{C}$ and the solution is stirred at room temperature and allowed to react. The solution gels in $3-4 \mathrm{~h}$ and is left to stand overnight. Heating to $80^{\circ} \mathrm{C}$ for periods as long as $10 \mathrm{~h}$ does not change the properties of the resultant gels. The solvent is removed by vacuum evaporation at $80^{\circ} \mathrm{C}$ to give a brittle, semi-transparent solid that is then ground for further studies. All of the studies presented below are based on this ground material which is described in more detail in Refs 26 and 27.

Simple molecular modeling (Cerius ${ }^{2}$ ) of the product of scheme 8 suggests that the crosslinked cubes might be cubic close-packed, as illustrated in Figures 5 and 6 , to give materials with very welldefined porosity.

Previous work by Hoebbel et al. ${ }^{23,24}$ and more

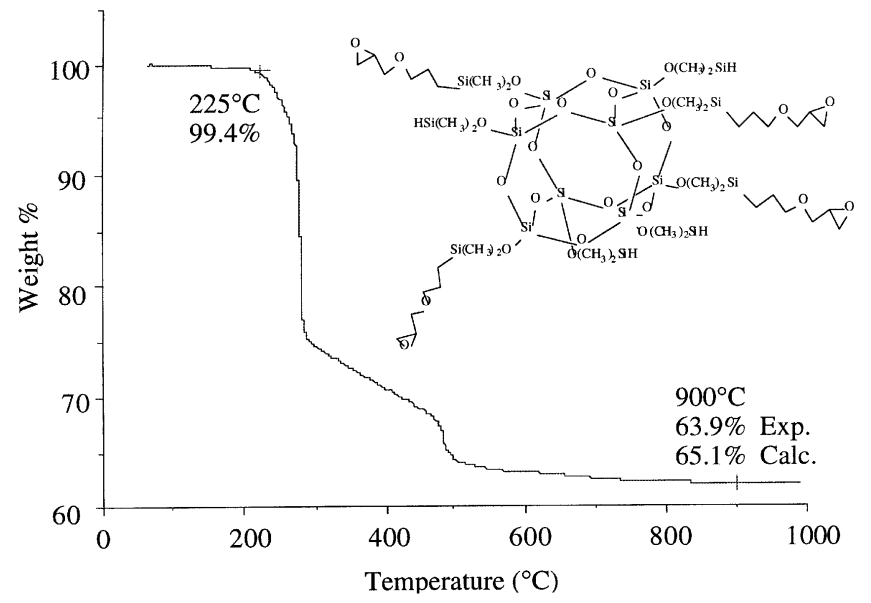

Figure 3 TGA of (glycidylD $)_{4}(\mathrm{HD})_{4} \mathrm{~T}_{8}$ cube. Average substitution $\approx 4$. 


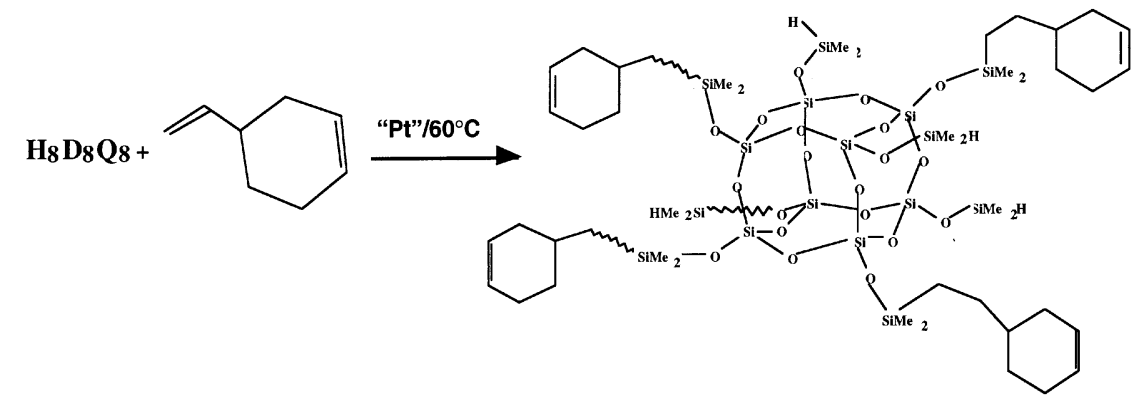

Scheme 7

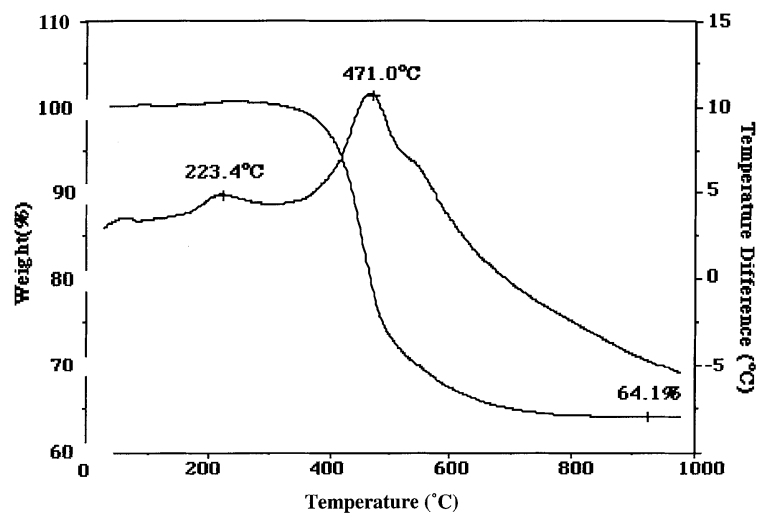

Figure 4 TGA/DTA of tetravinylcyclohexenyl-substituted cube heated at $10{ }^{\circ} \mathrm{C} \mathrm{min}^{-1}$ in air.

recent work by Harrison and Kannengieser, ${ }^{28}$ indicate that these and related cube materials offer quite high specific surface areas (SSAs), but no pore size distributions were reported. There are some inconsistencies with this earlier work, probably resulting from difficulties in obtaining good porosimetry data, because of the extended times required for data collection. ${ }^{26,27}$ The polymer formed in Scheme 8 has now been made many times and characterized in detail.

To establish the pattern of hydrosilylation, solidstate NMR studies were run. ${ }^{26,27,29}$ The results of both ${ }^{13} \mathrm{C}$ and ${ }^{29} \mathrm{Si}$ magic-angle spinning NMR coupled with IRCP (inverse recovery cross-polarization), which derives from a standard CP sequence and is based on polarization inversion, ${ }^{29}$ indicate that polymerization occurs solely by $\beta$ addition of $\mathrm{Si}-\mathrm{H}$ to vinyl groups to give ethylene, rather than methylene, bridges. The IRCP studies permit quantitative analysis of the crosslink density through integration of starting moiety and product peaks.
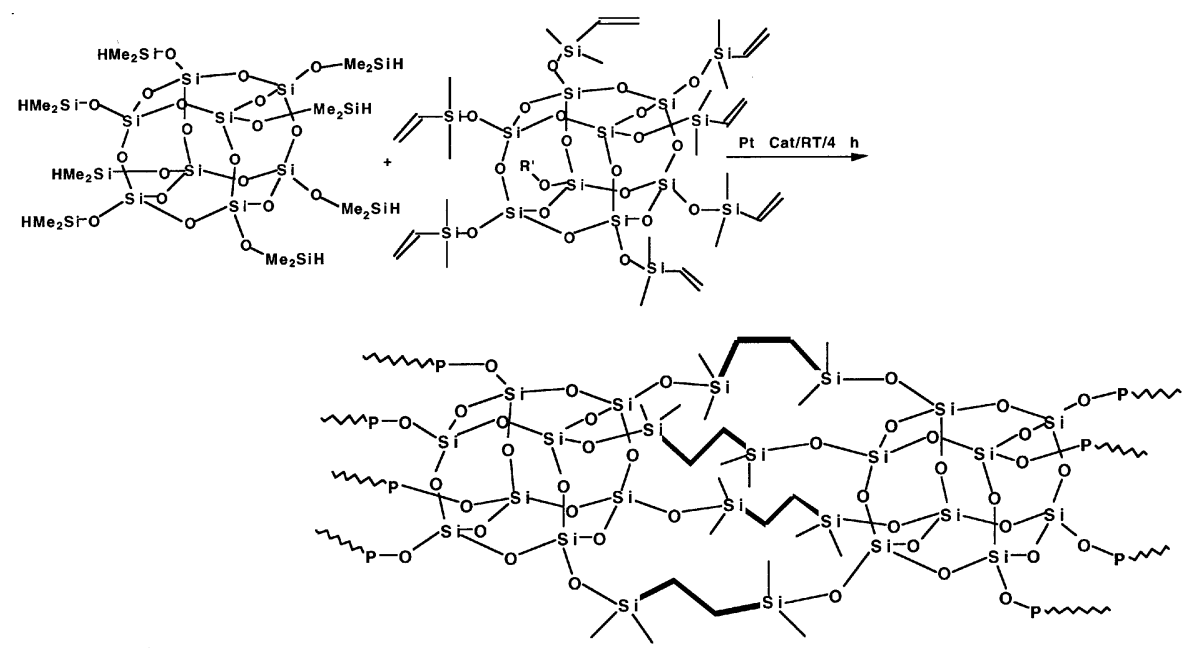

Scheme 8 


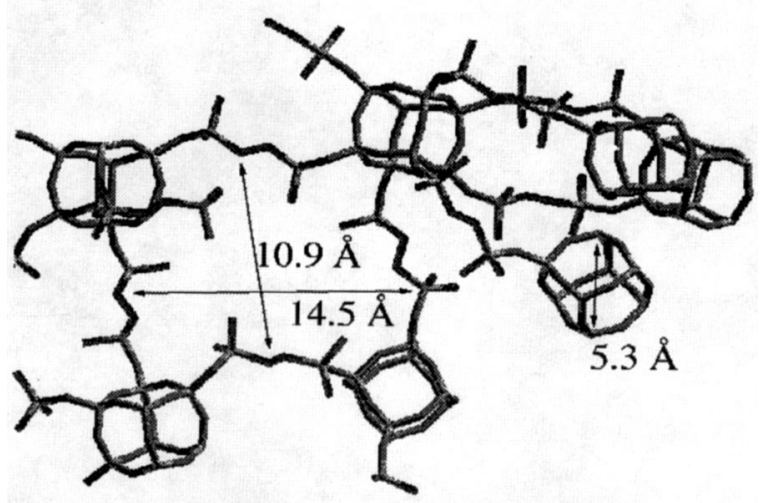

Figure 5 Cerius $^{2}$ model of spacer cube polymer with ethylenedisiloxane linkages. The cube body diagonal shown is for $\mathrm{Si}-\mathrm{Si}$ centers; the actual void diameter is $3-4 \AA$.

Both ${ }^{13} \mathrm{C}$ and ${ }^{29} \mathrm{Si}$ analyses indicate that Scheme 8 proceeds to give $81 \pm 1 \%$ crosslinking. Thus an average of 6.5 groups/cube participate in crosslinking. This is an unusually high proportion and suggests that polymerization involves multiple and sequential hydrosilylation reactions between the incoming reactant cube and the 'receiving' cube. $^{26,27}$ The 'receiving' cube may be part of a growing network. The very high degree of poly-

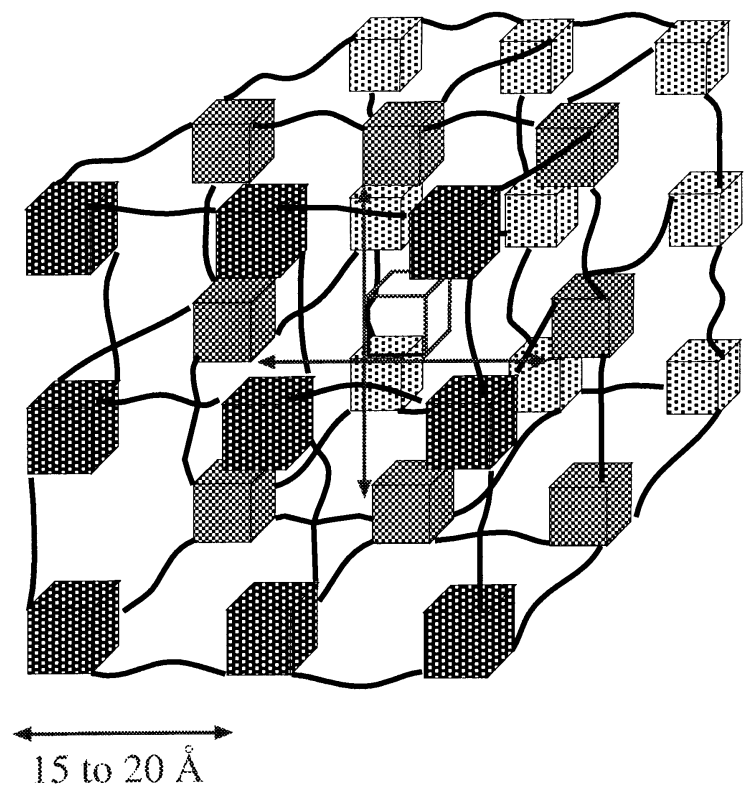

Figure 6 Packing model for a cube polymer with a defect site shown. Defect pore diameter $\approx 20-40 \AA$, depending on the degree of polymerization of the cubes at the pore surfaces.

(C) 1998 John Wiley \& Sons, Ltd.

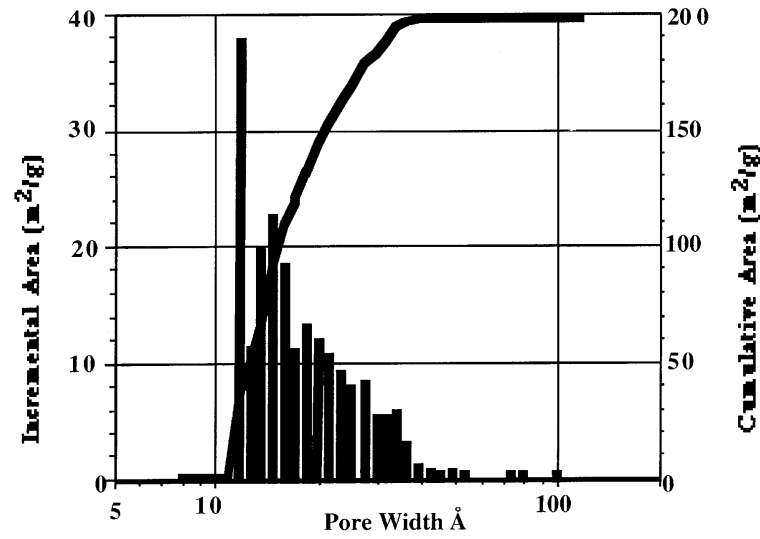

Figure 7 Cumulative and pore surface area distribution. Specific surface area $\approx 400 \mathrm{~m}^{2} \mathrm{~g}^{-1}$.

merization suggests that ordering of the cubes, such as shown in Figures 5 and 6, is highly likely. This in turn suggests that the pores between the cubes should be very well defined. This appears to be the case, as found from porosimetry measurements. 26,27,29

Figures 7 and 8 provide porosimetry data for the product of Scheme 8 . The total specific surface area for these materials ranges from 390 to $410 \mathrm{~m}^{2} \mathrm{~g}^{-1}$. The pore size distribution in Figure 8 is extremely unusual. Basically, the largest pores seen are $\approx$ $40 \mathrm{~A}$ in size. The smallest pores observed are in the $10-12 \AA$ range. These latter pores correspond in size to the intercube pores suggested to exist according to the Figure 5 Cerius ${ }^{2}$ model. The larger pores might arise because of defects in the polymer structure, where whole cubes are missing, as suggested in Figure 6. Small-angle X-ray scattering (SAXS) and positron annihilation lifetime (PALS)

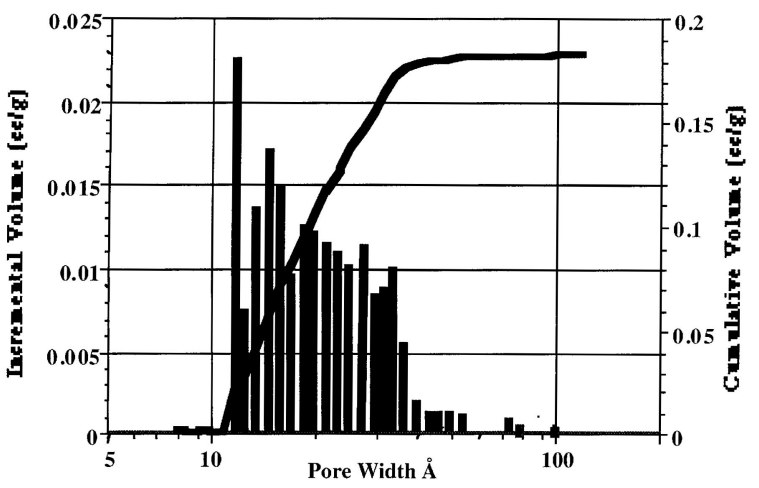

Figure 8 Pore volume distribution.

Appl. Organometal. Chem. 12, 715-723 (1998) 
studies confirm the existence of the smaller, 10$12 \AA$, pores as well as the $3-4 \AA$ interior pores. The interior pores contribute an additional $0.05 \mathrm{mlg}^{-1}$ of pore volume that is not seen by BET analysis. $^{26,27}$

Taken in toto, the data provide excellent evidence for polymerization inducing a high degree of organization in the hybrid material of scheme 8 . Although we did not expect the results, it appears that the polymerization process leads to high-SSA porous materials with exceptional control of the pore sizes and size distributions. An additional observation, made by comparing PALS data at 30 and $-50{ }^{\circ} \mathrm{C}$ with TMA data, ${ }^{26,27}$ is that the cube interior pores change very little over the $-50-30{ }^{\circ} \mathrm{C}$ temperature range whereas the intercube pores resulting from polymerization change in size, exhibiting a coefficient of thermal expansion typical of polymeric materials. Thus, the composite materials respond to temperature changes as if they were polymeric. They also exhibit thermal stabilities on the order of those seen in Figure 4. ${ }^{26,27}$

\section{CONCLUSIONS}

From the above work, it is possible to draw reasonable conclusions about the utility of hybrid materials, even if we rely solely on the product of scheme 8. First, this high-surface-area, controlledporosity material most probably has a relatively low density in comparison with silica. Consequently, there is considerable potential for use as a lowdielectric material in the manufacture of ultrahighdensity, large-scale integrated circuits. ${ }^{30-33}$

If we also consider that one to two $\mathrm{Si}-\mathrm{H}$ and $\mathrm{Si}$ vinyl groups remain available for further chemical elaboration, then we can envision making novel optical materials, new catalyst systems and unusual membrane materials. ${ }^{34-37}$ Furthermore, we now have evidence that by changing the molar ratio of the two octafunctional materials in scheme 8 , one can control the pore size distribution and the chemistry at the resulting pore surfaces. ${ }^{26,27}$ Thus, just scheme 8 offers many potential avenues for further research. If we consider the products from scheme 7, another world of possibilities opens up. Thus, the potential utility of functionalized cubic silsesquioxanes for producing hybrid materials appears to be exceptional.

Acknowledgments We thank the Federal Aviation Administration for generous support of the work on the high-

(C) 1998 John Wiley \& Sons, Ltd. temperature stable and porous polysilsesquioxanes through Contract No. 95-G-026. We thank the National Institutes of Dental Research for supporting the work on LC- modified and epoxy-modified silsesquioxane syntheses.

\section{REFERENCES}

1. P. Judeinstein and C. Sanchez, J. Mater. Chem. 6, 511 (1996).

2. C. Sanchez, in:Materiaux Hybrides, Masson, Paris, 1996, pp. 27-31.

3. M. G. Voronkov and V. I. Lavrent'yev, Top. Curr. Chem. 102, 199 (1982).

4. R. H. Baney, M. Itoh, A. Sakaibara and T. Suzuki, Chem. Rev. 95, 1409 (1995).

5. J. D. Lichtenhan, N. Q. Vu, J. A. Carter, J. W. Gilman and F. J. Feher, Macromolecules 26, 2141 (1993).

6. T. S. Haddad and J. D. Lichtenhan, Am. Chem. Soc. Polym. Prepr. 35, 708 (1994).

7. J. D. Lichtenhan, R. A. Mantz, P. F. Jones and M. J. Carr, Am. Chem. Soc. Polym. prep. 35, 523 (1994).

8. T. S. Haddad and J. D. Lichtenhan, J. Inorg. Organometal Polym. 3 (5), 237 (1995).

9. F. J. Feher, D. A. Newman and J. F. Walzer, J. Am. Chem. Soc. 111, 1741 (1989).

10. A. Sellinger and R. M. Laine, Polym. Prepr. 35, 665 (1994).

11. A. Sellinger, R. M. Laine, V. Chu and C. Viney, J. Polymer Sci.: Part A, Polym. Chem. 32, 3069 (1994).

12. A. Sellinger and R. M. Laine, Macromolecules 29, 2327 (1996).

13. A. Sellinger and R. M. Laine, Chem. Mater. 8, 1592 (1996).

14. C. Zhang and R. M. Laine, J. Organometal Chem. 521, 199 (1996).

15. P. A. Agaskar, Inorg. Chem. 30, 2707 (1991).

16. P. A. Agaskar, Colloids Surf. 63, 131 (1992).

17. P. A. Agaskar, Synth. React. Inorg. Met.-Org. Chem. 20, 483 (1990).

18. P. A. Agaskar, J. Am. Chem. Soc. 111, 6858 (1989).

19. K. Olsson, Ark. Kemi. 13, 367 (1958).

20. I. Hasegawa, S. Sakka, Y. Sugahara, K. Kuroda and C. Kato, J. Chem. Soc., Chem. Commun. 208 (1989).

21. I. Hasegawa and S. Motojima, J. Organometal Chem. 441, 373 (1992).

22. I. Hasegawa, J. Sol-Gel Sci. Technal. 2, 127 (1994).

23. D. Hoebbel, I. Pitsch and D. Heidemann, Eurogel 91, 1992, pp. $467-473$.

24. D. Hoebbel, K. Endres, T. Reinert and T. Pitch, J. NonCryst. Solids 176, 1788 (1994) and references therein.

25. C. Zhang, T. Bunning and R. M. Laine, manuscript in preparation.

26. C. Zhang, F. Babonneau, C. Bonhomme, R. M. Laine, C. L. Soles, H. A. Hristov and A. F. Yee, J. Am. Chem. Soc. (in press).

27. C. Zhang, R. Baranwal and R. M. Laine, Polym. Prepr. Am. Chem. Soc. Div. Polym. Chem. 36, 342 (1995).

Appl. Organometal. Chem. 12, 715-723 (1998) 
28. P. G. Harrison and R. Kannengiesser, J. Chem. Soc. Chem. Commun. 415 (1996).

29. C. Bonhomme, P. Toledano, J. Maquet, J. Livage and L. Bonhomme-Coury, J. Chem. Soc., Dalton Trans. 1617 (1997).

30. S.-P. Jeng, K. Taylor, T. Seha, M.-C. Chang J. Fattaruso and R. H. Havemann, Highly porous interlayer for interconnect capacitance reduction,Symp. VLSI Technol, Digest of Tech. papers, Japanese Society of Applied Physics, Tokyo,1995 pp. 61-62.

31. M. D. Nyman, S. B. Desu and C. H. Peng, Chem. Mater. 5, 1636 (1995).
32. L. A. Haluska, K. W. Michael and L. Tarhay, US Patent 4 756977 , July 1988.

33. See Dow Corning Inc. Fact Sheets on Flowable Oxide ${ }^{\mathrm{TM}}$.

34. L. C. Klein (ed.), Sol-Gel Optics: Processing and Applications, Kluwe Academic, Dordrecht (1983)

35. S. Rubinsztajn, M. Zeldin and W. K. Fife, Macromolecules 24, 2682 (1991).

36. G.-H. Hsiue, R.-H. Lee and R.-J. Jeng, Chem. Mater. 9, 883 (1997).

37. B. Dunn and J. I. Zink, J. Mater. Chem. 1, 903 (1991). 